\title{
Epidural analgesia in early labour blocks the stress response but uter- ine contractions remain unchanged
}

Timothy J. Scull MBBS, Gisèle T. Hemmings $M D$, Franco Carli MD MPHIL, Sally K. Weeks MBBS, Louise Mazza BSc, Hans H. Zingg PhD*

Purpose: To determine the effect of epidural analgesia on biochemical markers of stress, plasma oxytocin concentrations and frequency of uterine contractions during the first stage of labour.

Methods: Nine nulliparous women, in spontaneous labour, with a singleton fetus and cervical dilatation $\leq 5 \mathrm{~cm}$ were enrolled. Epidural bupivacaine $0.25 \%$ (range $10-14 \mathrm{ml}$ ) was administered and bilateral sensory blockade to ice $\left(T_{8}\right.$ $-L_{4}$ ) achieved. Blood samples were collected before the epidermal block and every $10 \mathrm{~min}$ for one hour after the block was achieved for the measurement of plasma beta-endorphin, cortical, glucose, lactate and oxytocin concentrations. No exogenous oxytocin was given. Intensity of pain was assessed at the time of the blood sampling using a $10 \mathrm{~cm}$ visual analogue scale (NAS). The frequency of uterine contractions was recorded for $60 \mathrm{~min}$ before and after the epidural block.

Results: There was a decrease in plasma beta-endorphin and cortisol concentrations after epidural block $(P<0.01)$. There were no changes in plasma glucose and lactate concentrations. The mean VAS for pain decreased 10 min after epidural block was achieved and remained $<2$ throughout the study period $(P<0.001)$. Mean plasma oxytocin concentrations did not change. The frequency of uterine contractions before and after the epidural block was similar.

Conclusions: The metabolic stress response to the pain of labour was attenuated by epidural analgesia. In contrast, plasma oxytocin concentration and frequency of uterine contractions were unaffected by the attenuation of metabolic stress response.

Objectif : Déterminer l'effet de l'analgésie péridurale sur les marqueurs biochimiques de stress, les concentrations plasmatiques d'oxytocine et la fréquence des contractions utérines pendant le premier stade du travail.

Méthode : Neuf femmes nullipares, en travail spontané, porteuse d'un seul foetus et présentant une dilatation du col de l'utérus $\leq 5 \mathrm{~cm}$, ont été recrutées. On a administré de la bupivacaiine péridurale à $0,25 \%$ (de 10 à $14 \mathrm{ml}$ ) et on a procédé à un blocage sensoriel bilatéral à la glace $\left(T_{8}-L_{4}\right)$. On a prélevé des échantillons de sang avant le point dermique et à toutes les 10 minutes pendant une heure après le bloc afin de mesurer les concentrations plasmatiques de B-endorphine, de cortisol, de glucose, de lactate et d'oxytocine. On n'a pas administré d'oxytocine exogène. Lintensité de la douleur a été évaluée au moment des prélèvements sanguins en utilisant une échelle visuelle analogique (EVA) de $10 \mathrm{~cm}$. La fréquence des contractions utérines a été enregistrée pendant 60 minutes avant et après l'analgésie péridurale.

Résultats : On a observé une baisse de la B-endorphine plasmatique et des concentrations de cortisol après l'analgésie péridurale $(P<0,01)$. II n'y a pas eu de changements dans les concentrations de glucose et de lactate. La moyenne de l'EVA pour la douleur a diminué, 10 minutes après le bloc péridural et est demeurée $<2$ pendant toute la durée de l'étude $(P<0,001)$. Les concentrations moyennes d'oxytocine n'ont pas changé. La fréquence des contractions utérines avant et après l'analgésie péridurale était similaire.

Conclusion : La réaction métabolique d'alarme liée aux douleurs de l'accouchement a été atténuée par l'analgésie péridurale. Par ailleurs, les concentrations plasmatiques d'oxytocine et la fréquence des contractions utérines niont pas été affectées par l'atténuation de la réaction métabolique.

From the Department of Anesthesia and Laboratory of Molecular Endocrinology, ${ }^{*}$ McGill University, Montréal, Québec, H3A 1Al Canada. Address correspondence to: Gisèle T. Hemmings MD, Department of Anesthesia, McGill University, Royal Victoria Hospital, 687, Pine Avenue West, Room F9.16, Montréal, Québec, Canada, H3A lAl. Fax: 514-843-1488; Phone: 514-842-1231, Ext. 5345 Supported by the McGill and Royal Victoria Hospital Departments of Anesthesia.

Accepted for publication March 21, 1998. 
$\mathrm{T}$ HE effect of epidural analgesia on the progress and outcome of labour has recently received great attention. Provision of epidural analgesia may lead to prolongation of the first and second stages of labour and increase in instrumental and operative deliveries for dystocia in nulliparous women. ${ }^{1,2}$ This has been contradicted in two prospective studies which showed that the administration of epidural analgesia between 3 and $5 \mathrm{~cm}$ cervical dilatation did not contribute to a greater incidence of Caesarean section. ${ }^{3,4}$ These clinical studies have not attempted to determine the effect of epidural analgesia on the mechanism that controls labour.

The control of uterine function during labour involves myogenic factors, upon which are superimposed neurogenic and hormonal control mechanisms. ${ }^{5}$ Oxytocin from the posterior pituitary is the main hormone implicated in the promotion of uterine contractions, although it is clear that oxytocin secretion has a role in initiating labour. The diverse actions of oxytocin during labour are mediated by specific high affinity oxytocin receptors present in the uterus. ${ }^{6}$ The circulating concentrations of oxytocin increase progressively during the first and second stages of labour, with a strong correlation between plasma oxytocin concentration and the frequency, but not the intensity, of uterine contractions. ${ }^{7}$ Other hormones such as prostaglandins and interleukins may play a role in oxytocin receptor regulation.

The pain associated with established labour correlates with increases in stress hormones. ${ }^{8}$ It is, therefore, possible that alterations of these biochemical mediators may influence oxytocin concentrations and receptor activity ultimately affecting the progress of labour.

Epidural local anaesthetics administered during labour have been shown to decrease the maternal circulating concentrations of cortisol, ${ }^{8}$ catecholamines $^{8}$ and beta-endorphin ${ }^{9}$ indicating a pivotal role of epidural blockade in modulating afferent nociceptive stimuli. However, it is not clear whether provision of analgesia influences plasma concentrations of oxytocin. While Goodfellow et al. ${ }^{10}$ reported a decrease in plasma concentration of oxytocin with epidural analgesia, this was not confirmed by Behrens et al. ${ }^{11}$ and de Geest et al. ${ }^{12}$ Unfortunately these investigators did not standardize the medications used to initiate epidural analgesia, the sensory distribution of analgesia, the stage of labour or the use of exogenous oxytocics. In addition, the use of intravenous fluid bolus before the epidural block was not documented. A large volume of iv fluid bolus has been shown to decrease uterine activity. ${ }^{13}$

The purpose of this investigation was to determine the effect of epidural analgesia on the metabolic stress response to pain of labour, plasma oxytocin concen- trations and frequency of uterine contraction.

\section{Methods}

The study was approved by the Institutional Ethics Committee, and written informed consent was obtained from all subjects at admission to the labour ward. Nine nulliparae at term gestation and in early phase of labour were enrolled. Inclusion criteria were: ASA $l$ and 2, nulliparity, term gestation, singleton fetus, spontaneous onset of labour with cervical dilatation $\leq 5$ $\mathrm{cm}$. Patients who had received oxytocin or opioids before the study were excluded. Other exclusion criteria were preeclampsia, diabetes, opioid abuse and betablocker therapy. Assessment of cervical dilatation was done at the time of the request for epidural analgesia.

The study period started when the patient requested epidural analgesia. No intravenous preload with normal saline was given. A 16 gauge cannula was inserted in the contralateral antecubital fossa for blood sampling. The first blood sample (baseline), withdrawn without the use of tourniquet, was taken at least $30 \mathrm{~min}$ from the last vaginal examination to minimize the possible neurogenic stimulus of uterine origin. ${ }^{14}$ At this time, intensity of labour pain was also assessed using a $1-10 \mathrm{~cm}$ visual analogue scale (VAS).

An epidural catheter was then placed at $\mathrm{L}_{2 \cdot 3}$ or $\mathrm{L}_{3.4}$ with the patient in the sitting position. Epidural labour analgesia was initiated utilizing $12 \mathrm{ml}$ bupivacaine $0.25 \%$ administered in three to four incremental boluses through the epidural catheter to achieve a bilateral sensory block to ice from dermatome $\mathrm{T}_{8}$ to $\mathrm{L}_{4}$. Left uterine displacement was maintained throughout the study period. The rate of $i v$ normal saline infusion, after the epidural block was established, was $4 \mathrm{ml} \cdot \mathrm{kg}^{-1} \cdot \mathrm{hr}^{-1}$. Maternal systolic blood pressure and pulse rate were recorded every five minutes for the first $20 \mathrm{~min}$ after epidural blockade. Hypotension (arterial systolic blood pressure $<90$ $\mathrm{mmHg}$ ) was treated with $0.1 \mathrm{mg}$ phenylephrine $i v$. The fetal heart was continuously monitored using external electrodes, and oxytocin augmentation, artificial rupture of membranes and vaginal examination were withheld throughout the study period.

After a bilateral sensory block was achieved (Time $=$ 0 ), blood sampling and VAS score were performed at the following times: $10(\mathrm{~T}=10), 20(\mathrm{~T}=20), 30(\mathrm{~T}=$ $30), 40(\mathrm{~T}=40), 50(\mathrm{~T}=50)$ and $60(\mathrm{~T}=60) \mathrm{min}$.

The frequency of uterine contractions was measured from tocographic recordings over one hour before and after the epidural block.

\section{Biochemical assays}

Blood samples were immediately centrifuged at $4^{\circ} \mathrm{C}$. The supernatant was then separated and frozen in dry 
ice and stored at $-70^{\circ} \mathrm{C}$ for further analysis. All samples were assayed for beta-endorphin, cortisol, glucose, lactate and oxytocin.

Plasma beta-endorphin assay was performed using a ${ }^{125}$ I RIA kit (Incstar, MN, USA). The mean interassay and intraassay coefficients of variance were $8.1 \%$ and $9.86 \%$, respectively. Plasma cortisol concentrations were measured using the Ciba Corning ACS 180 automated immunoassay (Ciba Corning Diagnostics Corp., MA, USA). The mean interassay and intraassay coefficients of variance were $7.7 \%$ and $3 \%$, respectively. Plasma glucose was measured by a glucose-oxidase method using a Glucose Analyzer 2 (Beckman Instruments, Fullerton, CA, USA). The assay for plasma lactate was performed using the Synchron $C X 7$ system (Beckman Instruments, CA, USA). The lactic acid concentration in plasma, was determined by measuring the absorbance due to the chromophore using an endpoint technique. The mean interassay and intraassay coefficients of variance were $4.5 \%$ and $3 \%$, respectively. Plasma concentrations of oxytocin were measured by radioimmunoassay, using a specific rabbit anti-oxytocin antibody (Peninsula Laboratories, Belmont, CA, USA). Plasma samples were acidified by the addition of $1 \mathrm{~N} \mathrm{HCl}(0.2 \mathrm{ml} .1 \mathrm{ml}$ plasma) and extracted using Seppak $\mathrm{Cl} 8$ cartridges (Millipore). ${ }^{125} \mathrm{I}$-oxytocin was used as a tracer and goat anti-rabbit IgG serum (Peninsula) was used to precipitate oxytocin/antibody complexes. Mean recovery assessed by adding synthetic oxytocin to plasma samples was $86 \% \pm$ SEM $6 \%$. Assay data were computed using a four parameter logistic curve fitting program. Assay sensitivity was 1 pg per tube.

In addition, the duration of the first and second stages of labour, incidence of fetal heart deceleration, mode of delivery, baby weight and Apgar score were recorded.

\section{Statistical Analysis}

All assay results were analyzed by repeated measures ANOVA for multiple sampling (Statistica). All statistically significant results $(P<0.05)$ were further analyzed by Newman Keuls post-hoc test.

\section{Results}

Maternal demographic data, cervical dilatation at the time of insertion of the epidural blockade, duration of first and second stages of labour and weight of the baby are shown in Table I. At the beginning of the study, five women had intact membranes while four had spontaneous rupture of membranes before the epidural block. There were eight spontaneous vaginal deliveries and one Caesarean section for failure to progress in first stage. Segmental $\left(\mathrm{T}_{8}-\mathrm{L}_{4}\right)$ bilateral sensory analgesia was achieved in all the women studied with the initial bupivacaine dose, and maintained for the study with no further requirement. No episodes of hypotension requiring phenylephrine occurred, and no fetal heart decelerations were observed throughout the study period.

As shown in Table II, VAS decreased from baseline 10 min after epidural analgesia was achieved until the end of the study $(P<0.001)$. Mean plasma concentrations of beta-endorphin decreased in the $10 \mathrm{~min}$ sample and all subsequent samples $(P<0.0001)$. Mean plasma cortisol concentrations were decreased at 50 and $60 \mathrm{~min}(P<0.001)$. Mean plasma concentrations of glucose, lactate and oxytocin did not change from $\mathrm{T} 0$.

Circulating oxytocin concentrations showed remarkable consistency and did not change throughout the study period. (Table II, Figure). Of note, in two women, plasma oxytocin concentrations were high throughout the study and this accounted for the large standard deviation. The number of uterine contractions per hour before and after epidural analgesia was $4.9 \pm 1.4$ and $4.4 \pm 2.1$, respectively (NS). The Apgar scores in all newborn babies at $l$ and 5 min were $>7$.

TABLE I Demographic and outcome data.

\begin{tabular}{lll}
\hline & Median & Range \\
\hline Age (yr) & 31 & $25-41$ \\
Weight (kg) & 73 & $62-92$ \\
Baseline cervical dilatation (cm) & 3 & $1-5$ \\
Duration of lst stage (hr.min) & 11.50 & $3.00-29.30$ \\
Duration of 2nd stage (hr.min) & 1.55 & $1.00-3.06$ \\
Weight of baby (kg) & 3.151 & $2.725-3.655$ \\
\hline
\end{tabular}

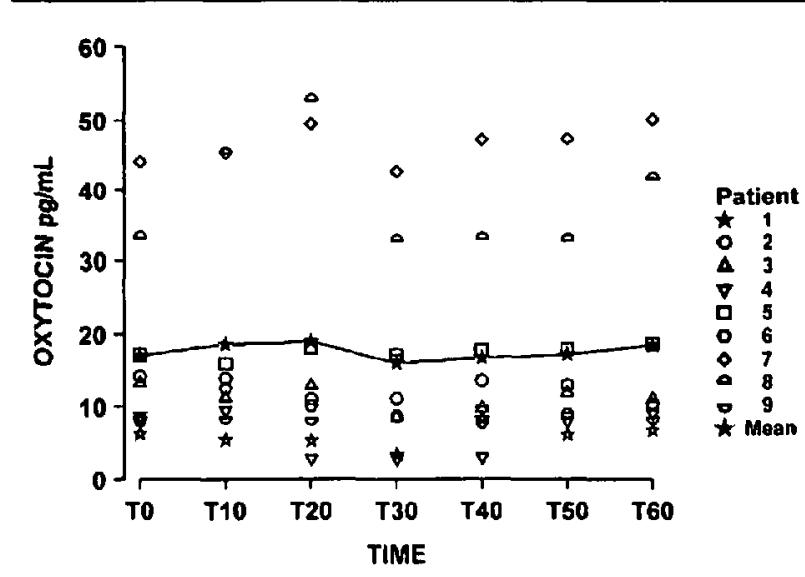

FIGURE Plasma oxytocin concentrations of individual patients at baseline and every $10 \mathrm{~min}$ for 60 min after epidural block. 
TABLE II VAS score and metabolic assays at baseline and at different intervals after epidural block. Mean \pm SD.

\begin{tabular}{|c|c|c|c|c|c|c|c|c|}
\hline & Baseline & $10 \mathrm{~min}$ & $20 \min$ & $30 \mathrm{~min}$ & $40 \mathrm{~min}$ & $50 \mathrm{~min}$ & $60 \mathrm{~min}$ & $P$ \\
\hline VAS & 7.26 & 1.87 & 1.24 & 0.97 & 0.78 & 0.87 & 0.84 & 0.0001 \\
\hline$(\mathrm{cm})$ & \pm 1.23 & \pm 0.25 & \pm 0.23 & \pm 0.10 & \pm 0.09 & \pm 0.08 & \pm 0.07 & \\
\hline beta-endorphin & 17.1 & 10.5 & 9.1 & 7.1 & 6.8 & 6.8 & 6.9 & 0.0001 \\
\hline$\left(\mathrm{pmol} \cdot \mathrm{L}^{-1}\right)$ & \pm 10.8 & \pm 6.2 & 4.5 & \pm 3.3 & \pm 2.4 & \pm 3.1 & \pm 2.8 & \\
\hline Cortisol & 1176 & 1123 & 1082 & 1144 & 1073 & 1017 & 989 & 0.001 \\
\hline (nmol. $\left.\mathrm{L}^{-1}\right)$ & \pm 316 & \pm 300 & \pm 355 & \pm 423 & \pm 313 & \pm 280 & \pm 223 & \\
\hline Glucose & 5.37 & 4.68 & 4.62 & 4.58 & 4.72 & 4.77 & 4.79 & 0.12 \\
\hline$\left(\mathrm{mmol} \cdot \mathrm{L}^{-1}\right)$ & \pm 1.28 & \pm 0.52 & \pm 0.63 & \pm 0.65 & \pm 0.67 & \pm 0.68 & \pm 0.75 & \\
\hline Lactate & 1.44 & 1.37 & 1.37 & 1.31 & 1.29 & 1.38 & 1.27 & 0.11 \\
\hline$\left(\mathrm{mmol} \cdot \mathrm{L}^{-1}\right)$ & \pm 0.3 & \pm 0.37 & \pm 0.39 & \pm 0.41 & \pm 0.31 & \pm 0.35 & \pm 0.34 & \\
\hline Oxytocin & 17.05 & 18.63 & 18.99 & 16.03 & 16.73 & 17.27 & 18.51 & 0.45 \\
\hline$\left(\mathrm{pg} \cdot \mathrm{ml}^{-1}\right)$ & \pm 12.96 & \pm 15.4 & \pm 18.73 & 13.46 & \pm 14.28 & 13.85 & \pm 16.0 & \\
\hline
\end{tabular}

VAS = visual analogue scale.

\section{Discussion}

All patients reported a decrease in VAS pain score within $10 \mathrm{~min}$ after epidural block indicating the establishment of effective pain relief. This was associated with a decrease in the circulating plasma concentration of beta-endorphin which has been shown to correlate well with subjective pain intensity. ${ }^{15,16}$

The mechanism by which beta-endorphin secretion is decreased following epidural blockade is not clear. It may result from blockade of the afferent limb of the reflex arc or from a generalised decrease in the stress response. The nociceptive impulses undergo modulation, transmission and dispersion within the central nervous system and initiate responses via the hypothalamic-pituitary and sympatho-adrenal axes, inducing a series of endocrine and metabolic changes. Markers of this stress response such as plasma cortisol, glucose and lactate (the latter indicating catecholamine activity) are increased during labour.

Epidural blockade with local anaesthetics has been reported to attenuate the response to surgical stress. In the present investigation, the mean plasma concentration of cortisol decreased, although delayed (50 $60 \mathrm{~min}$ ) during the study period. Mean plasma glucose and lactate did not, however, decrease. Markers of the stress response have been attenuated during Caesarean section when greater extent and intensity of neural blockade are needed. ${ }^{17}$

The precise role of oxytocin in the initiation and control of human labour is not known. At term, an increased number of receptors is found in both myometrium and decidua. ${ }^{18}$ It is reported that oxytocin acts at both sites, inducing contractions in the myometrium and an increase in synthesis of eicosanoids in the decidua. ${ }^{18,19}$ It is unclear what causes the initiation of labour in human subjects. It has been demonstrated that although plasma oxytocin concentrations do not increase before labour, they progressively increase. ${ }^{20}$ Plasma oxytocin concentration rises and falls in a pulsatile manner during labour, and increases in frequency throughout the first and second stages of labour. ${ }^{7}$ Pelvic visceral pressure, ${ }^{21}$ progressive cervical dilatation or possibly neurogenic stimuli directly from the body of the uterus ${ }^{14}$ may act as feedback stimuli. In addition, locally produced factors acting in a paracrine or autocrine fashion may play a role in oxytocin receptor regulation and in triggering parturition. Among these, prostaglandins and interleukins have attracted the most attention. ${ }^{22,23}$

Our results show a remarkable stability in circulating concentrations of oxytocin before and in the hour after the administration of epidural analgesia. These observations are consistent with previous reports that observed similar unchanged plasma oxytocin concentrations following epidural labour analgesia. ${ }^{11,12}$ In contrast to the small variation in plasma oxytocin levels in individual patients, we found large inter-patient variations indicating that different patients may vary considerably with respect to oxytocin secretion and/or degradation, but this process was not affected by epidural analgesia.

Although sampling was undertaken every $10 \mathrm{~min}$ in the current study it was not possible to observe the reported pulsatile nature of plasma oxytocin concentrations. However, precise assessment of pulsatility would have required sampling every minute and it would not have been acceptable to impose such a regimen.

The frequency, but not the intensity, of uterine contractions appears to be dependent upon plasma oxytocin concentrations. ${ }^{7}$ Therefore, the frequency of uterine contractions was recorded during the $60 \mathrm{~min}$ before and after epidural analgesia. Of importance, during the study period, the concentration of oxytocin remained unchanged, as did the frequency of uterine contractions. However, it is possible that the intensity of the uterine contractions or the fundal dominance 
pattern of contractions may have been altered during the study period, but the current study design did not permit assessment of these phenomena.

In conclusion, this investigation demonstrates that during the first hour following the initiation of epidural labour analgesia plasma beta-endorphin and cortisol concentrations decreased but no alteration in the plasma oxytocin or frequency of uterine contractions was observed. The sensory blockade attenuated the maternal response to stress and pain of parturition, but had no effect on oxytocin secretion or the frequency of uterine contraction. Therefore, it does not appear that the stress response modulates uterine function. If epidural analgesia interferes with the progress of labour, the mechanism is not through a decrease in oxytocin secretion.

\section{References}

1 Thorp JA, Hu DH, Albin RM, et al. The effect of intrapartum epidural analgesia on nulliparous labor: a randomized, controlled, prospective trial. Am J Obstet Gynecol 1993; 169: 851-8.

2 Read MD, Hunt LP, Anderton JM, Lieberman BA. Epidural block and the progress and outcome of labour. J Obstet Gynaecol 1983; 4: 35-9.

3 Chestnut DH, Vincent RD Jr, McGrath JM, Choi WW, Bates $J N$. Does early administration of epidural analgesia affect obstetric outcome in nulliparous women who are receiving intravenous oxytocin? Anesthesiology 1994; 80: 1193-200.

4 Chestnut DH, McGrath JM, Vincent RD Jr, et al. Does early administration of epidural analgesia affect obstetric outcome in nulliparous women who are in spontaneous labor? Anesthesiology 1994; 80: 1201-8.

5 Garfield RE. Control of myometrial function in preterm versus term labor. Clin Obstet Gynecol 1984; 27: 572-91.

6 Zingg HH, Rozen F, Chu K, et al. Oxytocin and oxytocin receptor gene expression in the uterus. Recent Prog Horm Res 1995; 50: 255-73.

7 Fuchs $A-R$, Romero $R$, Keefe D, Parra $M$, Oyarzun $F$, Behnke $E$. Oxytocin secretion and human parturition: pulse frequency and duration increase during spontaneous labor in women. Am J Obstet Gynecol 1991; 165: 1515-23.

8 Neumark J, Hammerle AF, Biegelmayer Ch. Effects of epidural analgesia on plasma catecholamines and cortisol in parturition. Acta Anaesthesiol Scand 1985; 29: 555-9.

9 Abboud TK, Sarkis F, Hung TT, et al. Effects of epidural anesthesia during labor on maternal plasma betaendorphin levels. Anesthesiology 1983; 59: 1-5.

10 Goodfellow CF, Hull MGR, Swaab DF, Dogterom J, Buijs RM. Oxytocin deficiency at delivery with epidural analgesia. Br J Obstet Gynaecol 1983; 90: 214-9.
11 Behrens $O$, Goeschen $K$, Luck H-J, Fuchs A-R. Effects of lumbar epidural analgesia on prostaglandin $\mathrm{F}_{2 \alpha}$ release and oxytocin secretion during labor. Prostaglandins 1993; 45: 285-96.

12 De Geest $K$, Thiery $M$, Piron-Possuyt $G$, Vanden Driessche $R$. Plasma oxytocin in human pregnancy and parturition. J Perinat Med 1985; 13: 3-13.

13 Cheek TG, Samuels P, Miller F, Tobin M, Gutsche BB. Normal saline i.v. fluid load decreases uterine activity in active labour. Br J Anaesth 1996; 77: 632-5.

14 Ferguson $J K W$. A study of the motility of the intact uterus at term. Surg Gynecol Obstet 1941; 73: 359-66.

15 Bacigalupo $G$, Riese $S$, Rosendabl $H$, Saling $E$. Quantitative relationships between pain intensities during labor and beta-endorphin and cortisol concentrations in plasma. Decline of the hormone concentrations in the early postpartum period. J Perinat Med 1990; 18: 289-96.

16 Cahill $C A$. Beta-endorphin levels during pregnancy and labor: a role in pain modulation? Nurs Res 1989 : 38: 200-3.

17 Loughran PG, Moore J, Dundee JW. Maternal stress response associated with Caesarean delivery under general and epidural anaesthesia. Br J Obstet Gynaecol 1986; 93: 943-9.

18 Casey ML, MacDonald PC. Biomolecular processes in the initiation of parturition: decidual activation. Clin Obstet Gynecol 1988; 31: 533-48.

19 Padayachi T, Norman RJ, Reddi K, Shweni PM, Philpott $R H$, Joubert SM. Changes in amniotic fluid prostanglandins with oxytocin-induced labor. Obstet Gynecol 1986; 68: 610-3.

20 Fuchs $A R$, Fuchs F, Husslein P, Soloff MS, Fernstrom MJ. Oxytocin receptors and human parturition: a dual role for oxytocin in the initiation of labor. Science 1982; 215: 1396-8.

21 Peeters $G$, Houvenaghel $A$. Reflex release of milk-ejection activity by stimulation of organs in the pelvic region in sheep as studied by cross-circulation experiments. J Endocrinol (London) 1973; 58; 53-66.

22 Novy MJ, Liggins GC. Role of prostaglandins, prostacyclin, and thromboxanes in the physiologic control of the uterus and in parturition. Semin Perinatol 1980; 4: 45-66.

23 Romero $R$, Mazor $M$, Tartakovsky B. Systemic administration of interleukin-l induces preterm parturition in mice. Am J Obstet Gynecol 1991; 165: 969-71. 